\title{
ULTRASOUND MEASUREMENTS OF ROTATOR CUFF TENDONS IN MALE ADULTS
}

\author{
Khawaja Muhammad Baqir Hassan, Atiq Ur Rehman Slehria*, Tathir Baqir Hassan, Shakil Sarwar, Irfan Najam Sheen, \\ Shamaila Manzoor, Syed Aown Raza Shah Bokhari \\ Combined Military Hospital Malir/National University of Medical Sciences (NUMS) Pakistan, *Armed Forces Institute of Radiology \& Imaging/National \\ University of Medical Sciences (NUMS) Rawalpindi Pakistan
}

\begin{abstract}
Objective: To establish the normative ultrasound values of tendons of rotator cuff muscles in local healthy male population. Study Design: Cross sectional study.

Place and Duration of Study: Department of Radiology, Combined Military Hospital Malir, from Oct 2019 to Mar 2020. Methodology: The sample of study was 456 shoulders of 228 patients. All the patients went under ultrasound shoulder in standard positions. Data were analyzed with statistical analysis program Statistical Package for the Social Sciences version 23. Results: In right dominance the mean thickness of the supraspinatus, infraspinatus, subscapularis and biceps tendons were tendon $4.63 \pm 0.45 \mathrm{~mm}, 3.90 \pm 0.73 \mathrm{~mm}, 4.55 \pm 0.74 \mathrm{~mm}$ and $3.55 \pm 0.54 \mathrm{~mm}$ respectively. The acromio-humeral interval was $12.63 \pm 2.005 \mathrm{~mm}$. In left dominance the mean thickness of the supraspinatus, infraspinatus, subscapularis and biceps tendons were $4.88 \pm 0.69 \mathrm{~mm}, 4.17 \pm 0.63 \mathrm{~mm}, 5.04 \pm 0.26 \mathrm{~mm}$ and $3.62 \pm 0.45 \mathrm{~mm}$ respectively. The acromio-humeral interval was 13.65 $\pm 2.98 \mathrm{~mm}$.
\end{abstract}

Conclusion: The study showed that there was insignificant difference between the dominant and non-dominant shoulders.

Keywords: Dominant, Non-dominant, Rotator cuff, Shoulder, Ultrasound.

How to Cite This Article: Hassan KMB, Slehria AR, Hassan TB, Sarwar S, Sheen IN, Manzoor S, Bokhari SARS. Ultrasound Measurements of Rotator Cuff Tendons in Male Adults. Pak Armed Forces Med J 2021; 71(5): 1529-1533. doi: https://doi.org/10.51253/pafmj.v71i5.4285

This is an Open Access article distributed under the terms of the Creative Commons Attribution License (https://creativecommons.org/licenses/by-nc/4.0/), which permits unrestricted use, distribution, and reproduction in any medium, provided the original work is properly cited.

\section{INTRODUCTION}

Shoulder pain is one of the common presenting complaints in day to day clinical practice. ${ }^{1}$ Pathologies of rotator cuff are one of the commonest causes of shoulder pain, accounting for up to $70-75 \%$ of the cases ${ }^{1}$. Other causes include impingement syndrome, bursitis and tenosynovitis. ${ }^{2}$ Magnetic resonance imaging (MRI) and magnetic resonance (MR) arthrography are said to have highest sensitivity and specificity technique for detecting pathologies of rotator cuff. ${ }^{3}$ However their limited availability and cost make it difficult for the Pakistani population to undertake these imaging techniques. ${ }^{3}$ Ultrasound (US) is widely used for reasons of being cost-effective and wide availability with addition of dynamic scanning which cannot be done in MRI. ${ }^{4}$ Ultrasound is said to be more accurate with a sensitivity range from $92.4-96 \%$ and a specificity range from 93-94.4\% for detecting full thickness tear and a sensitivity range from $66.7-84 \%$ and a specificity range from 89-93.5\% for partial thickness tear. ${ }^{5-7}$ Thus ultrasound has proved to be an effective and reliable method of measuring thickness of the tendon. ${ }^{7}$ It has been used in the diagnosis of enthesopathy of various tendons of body such as biceps and Achilles. ${ }^{8}$ Achilles tendon

Correspondence: Dr Khawaja Muhammad Baqir Hassan, Department of Radiology, AFIRI Rawalpindi Pakistan

Received: 10 May 2020; revision received: 10 Oct 2021; accepted: 15 Oct 2020 pathologies can also be reliably analyzed on ultrasound. ${ }^{9}$ The thickness of tendon is an important tool and the best way to analyze it by comparing it to the other shoulder. No such data is available in local population. Various international ultrasound studies have been published on various rotator cuff pathologies such as tear, tenosynovitis and tendinopathies. ${ }^{5}$ However, no local reliable reference for provision of normal ultrasound measurements of the shoulder with a wide reference of age groups, especially in the Pakistani population is currently available. In this study, the ultrasound measurements of the thickness of supraspinatus, infraspinatus and subscapularis tendons, long head of biceps tendon, and acromio-humeral interval in healthy Pakistani male adults were measured. The possible variability among dominant and non-dominant limbs, ethnicity and ages were analyzed to give reference ranges for measurements.

\section{METHODOLOGY}

This cross sectional study was conducted after approval from Ethical Committee of Combined Military Hospital, Malir from October 2019 and March 2020). The sample size of 456 shoulders was calculated by comparative cross sectional formula having the precision of $5 \%$ with $50 \%$ prevalence and confidence interval of $95 \%$. Informed consents were taken from the subjects. Frequencies, means and ranges for age, 
BMI and thicknesses of tendons and acromio-humeral interval were calculated.

All subjects were included in the study via open invitation who visited various out patient department of Combined Military Hospital Malir for medical examination for various courses.

Inclusion Criteria: Asymptomatic, healthy males having ages between 20-35 years with no past shoulder pathology were incorporated in the study.

Exclusion Criteria: Subjects with, myalgia shoulder, history of shoulder instability or dislocation, shoulder diseases such as rotator cuff injury, impingement syndrome, biceps tendinopathy, adhesive capsulitis, sub acromial bursitis, or acromio-clavicular joint injury, Past surgery of rotator cuff, Weak shoulder due neurological problems like suprascapular neuropathy, brachial plexopathy, cervical root disorder, cervical myelopathy and stroke diabetes mellitus, rheumatic disorders or systemic diseases (renal, hepatic, cardiac, etc.), body building or any other physical activity to increase the strength of muscles, Any prolonged treatment or stesteroids intake.

Physical examination was conducted by resident surgeon or medical officer in various OPD's to exclude any shoulder pathology. It included shoulder range of movements, palpation of shoulder joints, provocative tests for evaluation of gleno-humeral instability, labral pathology, rotator cuff injury, impingement syndrome, acromioclavicular joint pathology, bicep tendon injury were performed. Subjects developing pain, tenderness, showed decreased movement, or any affirmative findings during physical examination were excluded.

Demographic details including age, ethnicity and hand dominance were collected. Ultrasound examination was performed by a radiologist. Both shoulders were evaluated in each individual scan and results were noted for both dominant and non-dominant arms. My Lab, ${ }^{7}$ eSaote ultrasound Machine with, ${ }^{8-15}$ $\mathrm{MHz}$ linear array probe was used. Ultrasound was done according to the decorum recommended by the European Society of Musculoskeletal Radiology. ${ }^{10}$

The dimensions of following tendons and spaces were recorded, i) thickness of the subscapularis tendon, ii) thickness of the supraspinatus tendon, iii) thickness of the infraspinatus tendon, iv) thickness of the long head of biceps, iv) the acromio-humeral interval.

The thickness of long head of biceps tendon was measured in the neutral position of the arm with elbow flexed. The forearm was placed on the thigh and long head of biceps was visualized in the biccipital groove. The tendon of subscapularis muscle was visualized below coracoid process. Later on the probe was rotated some what internally to find its distal attachment to the lesser tuberosity ${ }^{11}$. Later on the patient was asked to externally rotate the arm while elbow flexed to clearly visualize the tendon. The subscapularis tendon thickness was recorded just medial to the insertion site. The modified crass position was used to measure the thickness of supraspinatus tendon ${ }^{12}$. The supraspinatus tendon was visualized on the coronal view at the sulcus between greater tuberosity and articular cartilage in the modified crass position. In this position, the probe was brought parallel to the supraspinatus tendon at the site of its attachment. The thickness of the tendon was measured. The reason for the modified crass position over the crass position is that it showed less discomfort to later on, the patient was asked to place the hand of the side being examined on the opposite shoulder. Then the thickness of the infraspinatus tendon was measured just next to the lesser tuberosity. If the patient feels distress, he was asked to place it onto the opposite thigh. The $\mathrm{AH}$ joint was measured also in the neutral position by keeping the probe longitudinal. The distance from inferior margin of the acromion to the margin of the humerus was measured by drawing a vertical line in between both the bones.

In order to achieve the desired objective, frequency and percentage, mean, standard deviation were calculated and t-test, were applied. Data ware analyzed with statistical analysis program ('Statistical Package for the Social Sciences" version 23).

\section{RESULTS}

A total of 228 volunteers were included in the study. About 456 shoulders from 228 subjects all males (212 right hand dominance and 16 left hand dominance, range of age 17-35 years) underwent shoulder sonography. Left hand dominance was noted in Punjabi and Urdu speaking volunteers only. The demographic details of the participants are shown in Table-I.

In our subjects, the mean thickness of supraspinatus, infraspinatus, subscapularis, biceps tendons and acromio-humeral interval were noted in accordance to dominance. In right side dominance the mean thickness (both sides combined) of the supraspinatus, infraspinatus, subscapularis and biceps tendons, was tendon $4.63 \pm 0.45 \mathrm{~mm}, 3.90 \pm 0.73 \mathrm{~mm}, 4.55 \pm 0.74 \mathrm{~mm}$ and $3.55 \pm 0.54 \mathrm{~mm}$ respectively. The acromio-humeral interval was found to be $12.63 \pm 2.005 \mathrm{~mm}$. 
In left side dominance the mean thickness (both sides combined) of the supraspinatus, infraspinatus, subscapularis and biceps tendons, was $4.88 \pm 0.69 \mathrm{~mm}$, $4.17 \pm 0.63 \mathrm{~mm}, 5.04 \pm 0.26 \mathrm{~mm}$ and $3.62 \pm 0.45 \mathrm{~mm}$ respectively. The acromio-humeral interval was found to be $13.65 \pm 2.98 \mathrm{~mm}$.

The comparative analysis of measurements of thickness of rotator cuff tendons, between two sides of same individuals was also done. When right side is dominant, measurement are shown in Table-III and that of left sided dominance in Table-III. Right and left hand dominance was also stratified by the ethnicity as well as shown in Table-IV \& V.

Table-I: Demographic details of the participants $(n=228)$.

\begin{tabular}{l|c|c|c}
\hline Characteristics & Frequency & \multicolumn{2}{|c}{ Dominance } \\
\hline Mean age (year) & $21.18 \pm 1.5$ & Right & Left \\
\hline Age range & $17-35$ years & \\
\hline Ethnicity & 28 & 21 & 7 \\
\hline Punjabi & 26 & 26 & - \\
\hline Pashtoon & 25 & 25 & - \\
\hline Balochi & 27 & 27 & \\
\hline Sindhi & 17 & 17 & \\
\hline Kashmiri & 105 & 96 & 9 \\
\hline Urdu Speaking & \multicolumn{3}{|l}{} \\
\hline Dominant Side of Limb (No.) & 212 & 16 \\
\hline Right & \multicolumn{3}{l}{} \\
\hline Left
\end{tabular}

Table-II: Comparison of two sides in right dominance.

\begin{tabular}{l|c|c}
\hline \multicolumn{3}{c}{ Right Dominant (n=212) } \\
\hline Muscle & Right & Left \\
\hline \multirow{2}{*}{ Supraspinatus } & $4.82 \pm 0.82$ & $4.45 \pm 0.03$ \\
& $(2.80-6.7)$ & $(2.10-6.4)$ \\
\hline \multirow{2}{*}{ Infraspinatus } & $3.93 \pm 0.76$ & $3.87 \pm 0.70$ \\
& $(2.20-6.2)$ & $(2.70-5)$ \\
\hline \multirow{2}{*}{ Subscapularis } & $4.82 \pm 0.79$ & $4.28 \pm 0.54$ \\
& $(2.60-6.9)$ & $(2.70-6.1)$ \\
\hline \multirow{2}{*}{ Biceps } & $3.63 \pm 0.6$ & $3.48 \pm 0.49$ \\
& $(2.00-5.20)$ & $(2.60-4.8)$ \\
\hline Acromio-Humeral & $12.52 \pm 2.13$ & $12.74 \pm 1.88$ \\
Interval & $(7.70-19.5)$ & $(9.0-18)$ \\
\hline
\end{tabular}

Table-III: Comparison of two sides in left dominance.

\begin{tabular}{l|c|c}
\hline \multicolumn{3}{c}{ Left Dominant (n=16) } \\
\hline Muscle & Right & Left \\
\hline \multirow{2}{*}{ Supraspinatus } & $4.56 \pm 0.54$ & $5.20 \pm 0.84$ \\
& $(4.00-5.30)$ & $(4.20-6.40)$ \\
\hline \multirow{2}{*}{ Infraspinatus } & $3.84 \pm 0.52$ & $4.51 \pm 0.75$ \\
& $(3.10-4.30)$ & $(3.80-5.60)$ \\
\hline \multirow{2}{*}{ Subscapularis } & $5.05 \pm 0.25$ & $5.03 \pm 0.27$ \\
& $(4.80-5.80)$ & $(4.70-5.50)$ \\
\hline \multirow{2}{*}{ Biceps } & $3.77 \pm 0.42$ & $3.48 \pm 0.49$ \\
& $(2.00-5.20)$ & $(2.60-4.80)$ \\
\hline Acromio-Humeral & $13.35 \pm 3.37$ & $14.00 \pm 2.59$ \\
Interval & $(7.70-18.00)$ & $(9.0-16.20)$ \\
\hline
\end{tabular}

\section{DISCUSSION}

Shoulder pain is a common complaint in general population of the world as well in Pakistan ${ }^{13}$. Various studies have been published internationally in this regard. ${ }^{14,15}$ In routine $X$-ray shoulder is being advised for such patients. It is not a significant imaging investigation in these patients. ${ }^{16}$ Ultrasound shoulder is an evolving imaging tool because of ease, low cost, being highly sensitive and specific. ${ }^{17}$ Many common pathologies have been easily diagnosed in patients especially without trauma. ${ }^{18}$ Now a days many ultrasound guided procedures and interventions are being performed.19,20 All these warrant normative values of the tendons thickness in local population. However, normative ranges for tendon thickness on ultrasound, in Pakistani adults of both genders, are not available. We recorded the subject thickness on ultrasound, the rotator cuff muscles that include supraspinatus, Infraspinatus, subscapularis and long head of biceps tendon in Pakistani healthy male adults. The acromiohumeral joint spaces of both sides were also measured.

Ultrasound of both the shoulders was done on 456 shoulders from 228 healthy male adults. The thicknesses of tendons of rotator cuff (supraspinatus, infraspinatus, and subscapularis tendon) and, long head of biceps tendon were recorded uniformly. ${ }^{21}$ The differences in the measurements with reference to age and side dominance were also compared. The values were also evaluated in relation to the various ethnic and regional backgrounds of Pakistan.

In our study, the thickness of rotator cuff ten-dons (supraspinatus, infraspinatus, and subscapularis) and biceps were not significantly different between dominant and non - dominant arms in same individual and similar age group. Although that some difference has been noted among dominant and non-dominant arms in various previous studies. ${ }^{14}$ Which means the other normal shoulder can be used to as normal reference for comparison in that individual. When grouped by age in years, the thicknesses of biceps, supraspinatus, subscapularis and infraspinatus tendons showed mixed pattern of values with the age. There was considerable difference between various ethnic groups for various tendons' thick nesses. Our study had similar results with previous studies with exception to that the results were similar in same ethnic groups and different in when compared to other groups. All the patients in the study were not performing any sort of exercise to avoid any bias. 
Table-IV: Mean thickness of tendons in $\mathrm{mm}$ in right hand dominant subjects.

\begin{tabular}{|c|c|c|c|c|c|c|c|c|c|c|c|c|}
\hline \multirow[t]{2}{*}{ Ethnicity } & \multirow[t]{2}{*}{$\begin{array}{c}\text { Age } \\
\text { (years) }\end{array}$} & \multirow[t]{2}{*}{ BMI } & \multicolumn{2}{|c|}{ Tendons } & \multirow[b]{2}{*}{ Rt SS } & \multirow[b]{2}{*}{ Rt IS } & \multirow[b]{2}{*}{ Lt Bi } & \multirow[b]{2}{*}{ Lt Sub } & \multirow[b]{2}{*}{ Lt SS } & \multirow[b]{2}{*}{ Lt IS } & \multicolumn{2}{|c|}{ AH Interval mm } \\
\hline & & & Rt Bi & $\begin{array}{c}\text { Rt } \\
\text { Subs }\end{array}$ & & & & & & & Rt AH & Lt AH \\
\hline Punjabi & $\begin{array}{c}25.56 \pm \\
3.66\end{array}$ & $\begin{array}{c}22.97 \pm \\
3.15\end{array}$ & $\begin{array}{c}3.49 \pm \\
0.80\end{array}$ & $\begin{array}{l}4.71 \pm \\
0.66\end{array}$ & $\begin{array}{c}4.53 \pm \\
0.63\end{array}$ & $\begin{array}{c}3.89 \pm \\
0.68\end{array}$ & $\begin{array}{c}3.20 \pm \\
0.44\end{array}$ & $\begin{array}{c}4.63 \pm \\
0.70\end{array}$ & $\begin{array}{c}4.34 \pm \\
0.66\end{array}$ & $\begin{array}{c}3.93 \pm \\
0.84\end{array}$ & $\begin{array}{c}13.73 \pm \\
2.74\end{array}$ & $\begin{array}{c}14.05 \pm \\
1.31\end{array}$ \\
\hline Pakhtoon & $\begin{array}{l}24 \pm \\
0.10\end{array}$ & $\begin{array}{c}20.80 \pm \\
2.70\end{array}$ & $\begin{array}{c}3.41 \pm \\
0.60\end{array}$ & $\begin{array}{c}3.71 \pm \\
0.56\end{array}$ & $\begin{array}{c}3.90 \pm \\
0.60\end{array}$ & $\begin{array}{c}3.40 \pm \\
0.61\end{array}$ & $\begin{array}{c}3.30 \pm \\
0.34\end{array}$ & $\begin{array}{c}4.40 \pm \\
0.60\end{array}$ & $\begin{array}{c}4.56 \pm \\
0.60\end{array}$ & $\begin{array}{c}3.10 \\
\pm 0.85 \\
\end{array}$ & $\begin{array}{c}11.30 \pm \\
2.54\end{array}$ & $\begin{array}{c}12.60 \pm \\
1.41\end{array}$ \\
\hline Balochi & $\begin{array}{l}22 \pm \\
0.25\end{array}$ & $\begin{array}{c}21.80 \pm \\
2.85\end{array}$ & $\begin{array}{c}4.50 \pm \\
0.55\end{array}$ & $\begin{array}{c}4.00 \pm \\
0.70\end{array}$ & $\begin{array}{c}3.90 \pm \\
0.55\end{array}$ & $\begin{array}{c}4.00 \pm \\
0.71\end{array}$ & $\begin{array}{c}3.50 \pm \\
0.29\end{array}$ & $\begin{array}{c}4.00 \pm \\
0.62\end{array}$ & $\begin{array}{c}4.60 \pm \\
0.70\end{array}$ & $\begin{array}{c}3.70 \pm \\
0.79\end{array}$ & $\begin{array}{c}11.70 \pm \\
2.44\end{array}$ & $\begin{array}{c}11.60 \pm \\
1.48\end{array}$ \\
\hline Sindhi & $\begin{array}{l}24 \pm \\
4.94 \\
\end{array}$ & $\begin{array}{c}20.97 \pm \\
2.32 \\
\end{array}$ & $\begin{array}{c}3.91 \pm \\
0.56 \\
\end{array}$ & $\begin{array}{c}5.23 \pm \\
0.62 \\
\end{array}$ & $\begin{array}{c}4.86 \pm \\
0.63 \\
\end{array}$ & $\begin{array}{c}4.18 \pm \\
0.48 \\
\end{array}$ & $\begin{array}{c}3.76 \pm \\
0.46 \\
\end{array}$ & $\begin{array}{c}4.85 \pm \\
0.83\end{array}$ & $\begin{array}{c}4.75 \pm \\
0.74 \\
\end{array}$ & $\begin{array}{c}4.30 \pm \\
0.49 \\
\end{array}$ & $\begin{array}{r}13.59 \\
\pm 2.78 \\
\end{array}$ & $\begin{array}{c}14.02 \pm \\
2.12 \\
\end{array}$ \\
\hline Kashmiri & $\begin{array}{c}26.33 \pm \\
0.48\end{array}$ & $\begin{array}{c}21.66 \pm \\
2.55\end{array}$ & $\begin{array}{c}4.46 \pm \\
0.09\end{array}$ & $\begin{array}{c}4.83 \pm \\
0.68\end{array}$ & $\begin{array}{c}4.86 \pm \\
0.25\end{array}$ & $\begin{array}{c}4.40 \pm \\
0.73\end{array}$ & $\begin{array}{c}3.16 \pm \\
0.17\end{array}$ & $\begin{array}{c}4.86 \pm \\
0.27\end{array}$ & $\begin{array}{c}5.36 \pm \\
0.39\end{array}$ & $\begin{array}{c}4.30 \pm \\
0.92\end{array}$ & $\begin{array}{l}14.73 \\
\pm 0.84 \\
\end{array}$ & $\begin{array}{c}14.70 \pm \\
0.85\end{array}$ \\
\hline $\begin{array}{l}\text { Urdu } \\
\text { Speaking }\end{array}$ & $\begin{array}{c}19.49 \pm \\
1.49 \\
\end{array}$ & $\begin{array}{c}20.26 \pm \\
2.74 \\
\end{array}$ & $\begin{array}{c}3.55 \\
\pm 0.54 \\
\end{array}$ & $\begin{array}{c}4.79 \pm \\
0.81 \\
\end{array}$ & $\begin{array}{c}4.78 \pm \\
0.89 \\
\end{array}$ & $\begin{array}{c}3.88 \pm \\
0.80 \\
\end{array}$ & $\begin{array}{c}3.48 \pm \\
0.49\end{array}$ & $\begin{array}{c}4.80 \pm \\
0.78 \\
\end{array}$ & $\begin{array}{c}4.49 \pm \\
0.86 \\
\end{array}$ & $\begin{array}{c}3.77 \pm \\
0.66 \\
\end{array}$ & $\begin{array}{c}12.09 \pm \\
1.17 \\
\end{array}$ & $\begin{array}{c}12.26 \pm \\
1.71\end{array}$ \\
\hline
\end{tabular}

Bi= Biceps, SS= Supraspinatus, IS = Infraspinatus, Sub= Subscapularis, AH = acromio-humeral Interval

Table-V: Mean thickness of tendons in $\mathrm{mm}$ in left hand dominant subjects.

\begin{tabular}{l|c|c|c|c|c|c|c|c|c|c|c|c}
\hline Ethnicity & $\begin{array}{c}\text { Age } \\
\text { (years) }\end{array}$ & BMI & Tendons & & & & & & & \multicolumn{2}{|c|}{$\begin{array}{c}\text { AH Interval } \\
\text { mm }\end{array}$} \\
\hline & & & Rt Bi & Rt ubs & Rt SS & Rt IS & Lt Bi & Lt Sub & Lt SS & Lt IS & Rt AH & Lt AH \\
\hline \multirow{2}{*}{ Punjabi } & $25 \pm$ & $21.19 \pm$ & $3.80 \pm$ & $5.00 \pm$ & $5.30 \pm$ & $4.30 \pm$ & $4.30 \pm$ & $5.30 \pm$ & $6.40 \pm$ & $5.66 \pm$ & 18.00 & $16.20 \pm$ \\
& 0.10 & 0.20 & 0.16 & 0.71 & 0.89 & 0.85 & 0.70 & 0.82 & 0.79 & 0.86 & \pm 2.10 & 2.51 \\
\hline Pushtoon & - & - & - & - & - & - & - & - & - & - & - & - \\
\hline Balochi & - & - & - & - & - & - & - & - & - & - & - & - \\
\hline Sindhi & - & - & - & - & - & - & - & - & - & - & - & - \\
\hline Kashmiri & - & - & - & - & - & - & - & - & - & - & - & - \\
\hline Urdu & $18.64 \pm$ & $17.59 \pm$ & $3.76 \pm$ & $5.07 \pm$ & $4.23 \pm$ & $3.63 \pm$ & $3.76 \pm$ & $4.90 \pm$ & $4.65 \pm$ & $4.02 \pm$ & 11.24 & $13.00 \pm$ \\
Speaking & 0.67 & 1.60 & 0.51 & 0.31 & 0.25 & 0.51 & 0.41 & 0.24 & 0.18 & 0.09 & \pm 1.18 \\
\hline
\end{tabular}

Bi= Biceps, SS= Supraspinatus, IS = Infraspinatus, Sub= Subscapularis, AH = acromio-humeral Interval

As there is no previous study giving normative reference ranges of rotator cuff tendon thickness in local population, this study provides these values in local adult males. It may become a useful reference while evaluating rotator cuff tendons' pathology. This study is of great value for the reason that it is the first provid normative ultrasound measurements of the rotator cuff in healthy Pakistani male adults.

In our study, no significant increase or decrease in tendon thick nesses was seen when compared with the age. Whereas in various other studies the stratification of the age has showed some increase in the tendon thickness when age also increase. ${ }^{14}$ However our study didn't include the subjects above 35 years. Therefore, there may be some relationship of the age in later years of the age which was not the scope of this study.

\section{LIMITATION OF STUDY}

This study has few limitations that are required to be considered. First, the ultrasound shoulder of one subject was performed by one radiologist and the measurements were not counter checked by the other radiologist, without knowing the prior measurements. This means intra-observer and inter-observer discrepancy was not evaluated. Few of pre- vious study regarding rotator cuff dimension in young healthy adults had shown significant intra-observer and interobserver agreement. In this study of sonographic evaluation of the shoulder, pathology was excluded, so it cannot be confirmed that difference of measurements between normal and abnormal sides exists or not.

\section{CONCLUSION}

There was insignificant difference between the dominant and non-dominant shoulders.

\section{Conflict of Interest: None.}

\section{Authors' Contribution}

KMBH: Data collection, Data analysis, ARS: Proof reading, TBH: Statistical design, SS: Samling collection, INS: literature review, SM: literature review.

\section{REFERENCES}

1. Lewis J. Rotator Cuff related shoulder pain. Advances in understanding and management. J Sci Med Sport 2017; 20(2): 47-52.

2. Lewis J. Rotator cuff related shoulder pain: assessment, management and uncertainties. Man Ther 2016; (23): 57-68.

3. Singh A, Thukral CL, Gupta K, Singh MI, Lata S, Arora RK. Role and correlation of high resolution ultrasound and magnetic resonance imaging in evaluation of patients with shoulder pain. Polish J Radiol 2017; 82(2): 410-415.

4. McNally EG, Rees JL. Imaging in shoulder disorders. Skeletal Radiol 2007; 36(11): 1013-1016. 


\section{Rotator Cuff Tendons}

5. Okoroha KR, Fidai MS, Tramer JS, Davis KD, Kolowich PA. Diagnostic accuracy of ultrasound for rotator cuff tears. Ultrasonog 2019; 38(3): 215-220.

6. Beggs I, Bianchi S, Bueno A, Cohen M, Court-Payen M, Grainger A. Musculoskeletal Ultrasound Technical Guidelines-Shoulder. [Internet] Available at: < https://essr.org/content-essr/uploads/ 2016/10/shoulder.pdf $>$ [Accessed on February 7,2020].

7. Naqvi GA, Jadaan M, Harrington P. Accuracy of ultrasonography and magnetic resonance imaging for detection of full thickness rotator cuff tears. Int J Shoulder Surg 2009; 3(4): 94-102.

8. McCormack RA, Nayyar S, Jazrawi L. Physician training: ultrasound and accuracy of diagnosis in rotator cuff tears. Bull Hosp Jt Dis (2013) 2016; 74(3): 207-212.

9. Wijesekera NT, Calder JD, Lee JC. Imaging in the assessment and management of Achilles tendinopathy and paratendinitis. Semin Musculoskelet Radiol 2011; 15(1): 89-93.

10. Gervasio A, Bollani P, Biasio A. US in mid-portion Achilles tendon injury. J Med Ultrasound 2014; 17(2): 135-139.

11. Gupta H, Robinson P. Normal shoulder ultrasound: anatomy and technique. Semin Musculoskelet Radiol 2015; 19(03): 203-211.

12. Beltran LS, Adler R, Stone T, Surace J, Beltran J, Bencardino JT. MRI and ultrasound imaging of the shoulder using positional maneuvers. Am J Roentgenol 2015; 205(3): W244-2W54.

13. Khan Y, Nagy MT, Malal J, Waseem M. Suppl 3: The painful shoulder: shoulder impingement syndrome. Open Orthop J 2013; 7(1): $347-352$.
14. Kim K, Kim HG, Song D, Yoon JY, Chung ME. Ultrasound dimensions of the rotator cuff and other associated structures in Korean healthy adults. J Korean Med Sci 2016; 31(9): 1472-1478.

15. Karthikeyan S, Rai SB, Parsons H, Drew S, Smith CD, Griffin DR. Ultrasound dimensions of the rotator cuff in young healthy adults. J Shoulder Elbow Surg 2014; 23(8): 1107-1112.

16. Salek KM, Mannan M, Chowdhury AZ, Haque MA, Kaiser MS, Nabi S, et al. Comparison between ultrasound and plain X-ray in evaluating the cause of shoulder pain. Mymensingh Med J 2011; 20(1): 16-21.

17. Martino F, Solarino M, Barile A, Di Fabio MV, Martino G Shoulder. In Measurements in Musculoskeletal Radiology 2020 Springer, Berlin, Heidelberg. [Internet] Available at: https:// www.springer.com/gp/book/9783540438533

18. Gupta PK, Uppal SS, Achuthan K, Adya CM, Singh A, Saini JS. Sonography: a valuable modality in evaluation of chronic nontraumatic disorders of the shoulder joint. Med J Arm For Ind 1998; 54(1): 27-31.

19. Chang KV, Mezian K, Naňka O, Wu WT, Lin CP, Özçakar L. Ultrasound-guided interventions for painful shoulder: from anatomy to evidence. J Pain Res 2018; 11(2): 2311-2315.

20. del-Olmo C, de-Diego P, Morillas P, Garcia-Navlet M. Ultrasound-guided pain interventions in shoulder region. Tech Reg Anesth Pain Manag 2013; 17(3): 81-95.

21. Lewis J. Rotator cuff related shoulder pain: Man Ther 2016; 23(2): 57-68. 